\title{
COMPARING ANALGESIC REQUIREMENTS AFTER A NON-OPIATE ANESTHESIA \\ AND AN OPIATE ANESTHESIA IN BREAST CANCER PATIENTS: A PROSPECTIVE RANDOMIZED, DOUBLE-BLINDED, CONTROLLED TRIAL
}

Authors: Saxena, S., Hontoir S., Gatto P., Sosnowski M.

Institute: Jules Bordet Institute, Dept. of Anaesthesiology, Brussels, Belgium

\section{BACKGROUND \& GOAL OF THE STUDY}

Opioids provide an excellent analgesic effect perioperatively, however, like every drug, not without side-effects. Post-operative complications, such as respiratory depression, post-operative nausea and vomiting, pruritus, difficulty voiding and ileus are well known.

In this study, analgesic requirement was examined after patients received opiate anesthesia and nonopiate anesthesia.

\section{MATERIALS \& METHODS}

A randomized controlled trial containing two groups with each 33 breast cancer patients undergoing a mastectomy or lumpectomy associated with a total axillary dissection was conducted between 29/09/2014 and 09/07/2015 at the Jules Bordet Institute, Brussels.

Per-operative non-opiate analgesia was obtained by combining clonidine $(0.2 \mathrm{mcg} / \mathrm{kg})$, ketamine $(0.3 \mathrm{mg} /$ $\mathrm{kg})$ and lidocaine $(1.5 \mathrm{mg} / \mathrm{kg})$. An extra bolus of ketamine $(0.2 \mathrm{mg} / \mathrm{kg})$ was given if necessary.

Opiate analgesia was obtained via a combination of remifentanil TCl, ketamine $(0.3 \mathrm{mg} / \mathrm{kg})$ and lidocaine $(1.5 \mathrm{mg} / \mathrm{kg})$.

Both groups received IV paracetamol (1000mg/6h) and IV diclofenac (75 mg/12h).

Patients received a PCA (patient-controlled analgesia) pump for breakthrough pain during the first 24 hours post-operatively.

Clinical characteristics and post-operative piritramide consumption were assessed during the first 24 hours post-operatively.

Non-parametric Wilcoxon test was used to compare postoperative piritramide consumption.

\section{RESULTS \& DISCUSSION}

Data were lacking for two patients in the non-opiate group. A total of 64 patients were included in the study.

In the PACU, immediate piritramide usage was 3.0 (2.0-6.0) $\mathrm{mg}$ in the opioid free group and 4.6 (4.0-6.0) in the opioid group. $(\mathrm{P}>0.05)$

The total piritramide usage 24 hours post-operatively was $8.1(2.0-14.5) \mathrm{mg}$ in the non-opiate group and $13.1(6.0-16.0) \mathrm{mg}$ in the opioid group. $(P<0.05)$

The difference observed was statistically significant. Thus, these values show that patients in the nonopiate group require less analgesics 24 hours postoperatively.

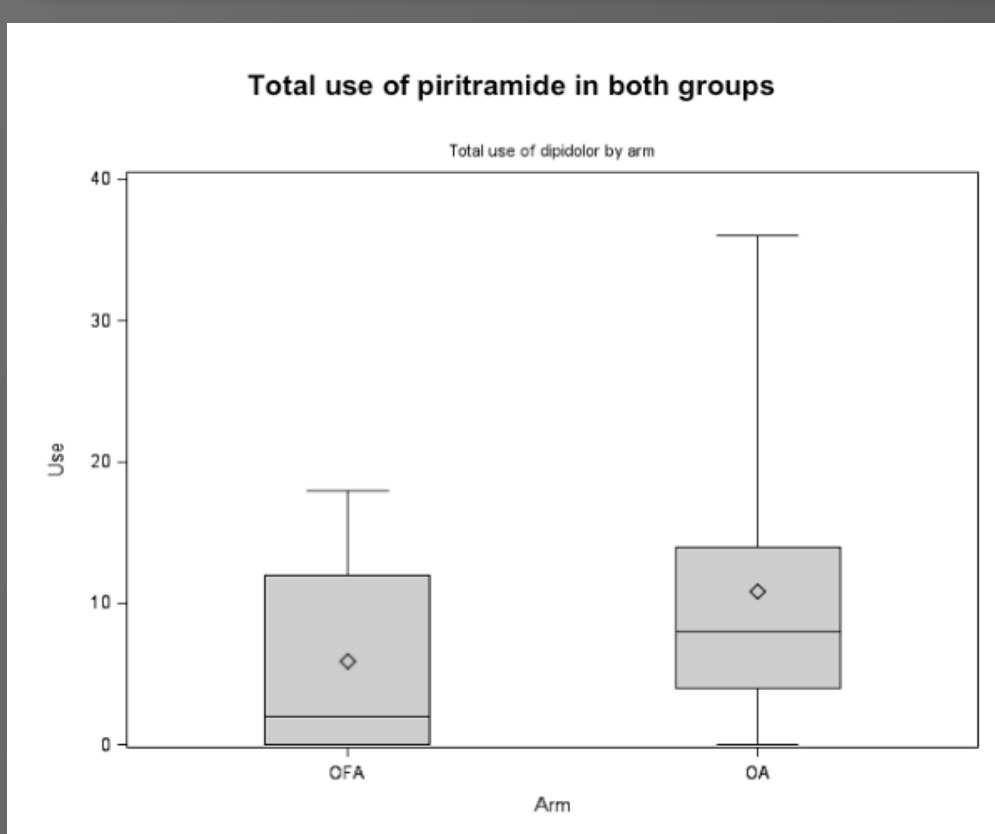

(OFA: opioid free anaesthesia) (OA: opioid anaesthesia)

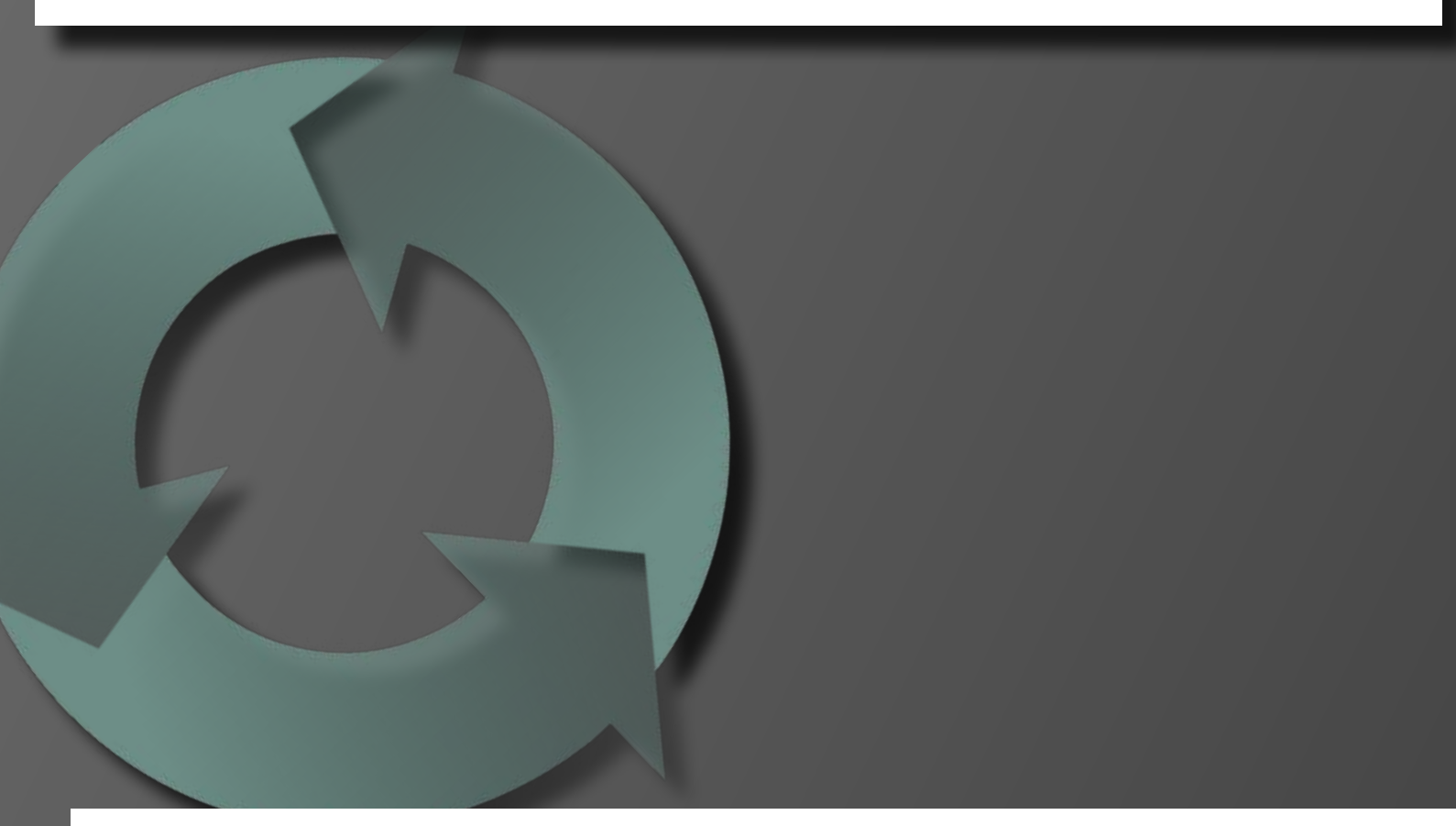

\section{CONCLUSION}

Anesthesia was uneventful in both groups.

Patients require less analgesics 24 hours after a nonopiate anesthesia than after an opiate anesthesia. 